\title{
In utero undernutrition reduces diabetes incidence in non-obese diabetic mice
}

\author{
A. Oge $\cdot$ E. Isganaitis $\cdot$ J. Jimenez-Chillaron $\cdot$ \\ C. Reamer • R. Faucette $\cdot$ K. Barry $\cdot$ R. Przybyla • \\ M. E. Patti
}

Received: 12 July 2006 / Accepted: 19 January 2007 / Published online: 17 March 2007

(C) Springer-Verlag 2007

\begin{abstract}
Aims/hypothesis Observational studies in humans suggest that low birthweight may decrease the risk of type 1 diabetes, but the mechanism is unknown. We hypothesised that antenatal undernutrition would decrease the incidence of type 1 diabetes in non-obese diabetic (NOD) mice.

Materials and methods A 40\% restriction of energy intake was applied to pregnant NOD dams from day 12.5 to day 18.5 of gestation, resulting in intrauterine growth retardation of offspring. All mice were fed a standard diet after weaning. Control and undernourished female offspring were followed to assess diabetes incidence. Male NOD mice were treated with cyclophosphamide to accelerate development of diabetes. Glucose homeostasis, body composition and pancreatic histology were compared in control and undernourished offspring.

Results Mean birthweight was lower in undernourished than in control mice $(p=0.00003)$. At 24 weeks of age, the cumulative incidence of spontaneous diabetes in female mice was $73 \%$ in control and $48 \%$ in undernourished mice $(p=0.003)$. In cyclophosphamide-treated male mice, antenatal undernutrition also tended to reduce the development of diabetes $(p=0.058)$. Maternal leptin levels were lower in undernourished dams on day 18.5 of pregnancy $(p=0.039)$, while postnatal leptin levels were significantly higher in undernourished offspring at 4, 20 and 27 weeks of life
\end{abstract}

A. Oge and E. Isganaitis, the first two authors, contributed equally to this manuscript.

A. Oge $\cdot$ E. Isganaitis $\cdot$ J. Jimenez-Chillaron $\cdot$ C. Reamer $\cdot$

R. Faucette $\cdot$ K. Barry $\cdot$ R. Przybyla $\cdot$ M. E. Patti $(\bowtie)$

Research Division, Joslin Diabetes Center,

Room 620, 1 Joslin Place,

Boston, MA 02215, USA

e-mail: mary.elizabeth.patti@joslin.harvard.edu $(p<0.05)$. Beta cell mass was similar in both groups (control $=0.4 \mathrm{mg}$; undernourished $=0.54 \mathrm{mg} ; p=0.24$ ). Histological evidence of apoptosis at 20 weeks was greater in control than in undernourished mice (control $=6.3 \pm$ $1.4 \%$; undernourished $=4.2 \pm 0.3 \%, p=0.05$ ).

Conclusions/interpretation Antenatal undernutrition reduces the incidence of diabetes in NOD mice, perhaps via alterations in apoptosis.

Keywords Apoptosis · Leptin · Low birthweight · Nonobese diabetic mice $\cdot$ NOD Type 1 diabetes mellitus
Abbreviations
DEXA dual-energy X-ray absorptiometry
NOD non-obese diabetic
TUNEL terminal deoxynucleotidyl transferase-mediated d-UTP nick-end labelling

\section{Introduction}

The intrauterine environment is increasingly recognised as a major determinant of patterns of disease during postnatal life. While much research has focused on the link between birthweight and later risk of cardiovascular disease, obesity and type 2 diabetes [1], epidemiological studies also suggest a link between birthweight and type 1 diabetes [2-4]. In contrast with the risk of type 2 diabetes, which is highest among both small- and large-for-gestational-age neonates [5], the incidence of type 1 diabetes increases linearly with birthweight $[6,7]$. Rates of type 1 diabetes have historically been lower among individuals born during periods of food scarcity, supporting a role for antenatal nutrition in disease pathogenesis [8]. Early postnatal life 
may also play an important role, with beta cell autoimmunity sometimes beginning in early infancy in individuals at high genetic risk [9]. Moreover, childhood growth patterns characterised by rapid weight [10] or height [11] gain are also associated with increased diabetes risk. Multiple lines of evidence, then, suggest that both antenatal and perinatal factors play a role in the pathogenesis of type 1 diabetes.

The mechanisms by which the intrauterine nutritional environment modulates the risk of type 1 diabetes are not well understood. The non-obese diabetic (NOD) mouse, one of the most widely used animal models of autoimmune diabetes, replicates some, but not all, of the complex pathophysiology of human type 1 diabetes. To our knowledge, the effects of in utero undernutrition on diabetes incidence in NOD mice have not been previously studied.

The aims of the present study were: (1) to examine the effects of intrauterine undernutrition on the incidence of diabetes in NOD mice; and (2) to characterise glucose homeostasis, leptin and insulin secretion, and pancreatic insulitis as functions of intrauterine undernutrition.

\section{Materials and methods}

Animal care and experimental method At 6 weeks of age female NOD mice (Jackson Laboratory, Bar Harbor, ME, USA) were randomly assigned to control or undernourished groups and mated with NOD males. Pregnancies were timed by presence of vaginal plug (day 0.5). In the undernourished group, maternal food intake was reduced by $40 \%$ (calculated from mean daily intake for pregnant control NOD) from days 12.5 to 18.5 of pregnancy, followed by free access to chow until delivery (control: day 19.5 ; undernourished: day $19.7 ; p=0.76$ ). Pups were weighed and marked with a tattoo as means of identification on day 1 of life. Litter size was standardised to five pups per nursing dam. Pups were permitted to nurse freely. At age 21 days, offspring were weaned to standard chow (LabDiet 9F; Purina Mills, St Louis, MO, USA). Mice were housed in the Joslin Diabetes Center Animal Facility (darklight cycle 06.00 to $18.00 \mathrm{~h}$ ). All animal protocols were approved by the Joslin Institutional Animal Use and Care Committee; Principles of Laboratory Animal Care (NIH publication 85-23, 1985; http:/grants1.nih.gov/grants/olaw/ references/phspol.htm) were followed.

In vivo metabolic evaluation To assess whether maternal undernutrition affected whole-body glucose metabolism in offspring, we measured fed and fasted glucose and insulin levels in control and undernourished offspring at age 8 weeks ( $n=8$ per sex and group). For all analyses, male and female mice were evaluated independently, unless otherwise specified. Intraperitoneal glucose tolerance tests $(2 \mathrm{~g} / \mathrm{kg})$ were performed in awake mice after a 16-h fast, with tail vein sampling for glucose at $0,15,30,60$ and $120 \mathrm{~min}$, and insulin measurements at 0 and $30 \mathrm{~min}(n=6$ per sex and group). Intraperitoneal insulin tolerance tests ( $1 \mathrm{U} / \mathrm{kg}$ regular human insulin) were performed in awake, fed mice at $14.00 \mathrm{~h}$, with glucose measured at $0,15,30$ and $60 \min$ ( $n=6$ per sex and group), using a commercially available device (Glucometer Elite; Bayer, Mishawaka, IN, USA). Serum insulin levels were measured by ELISA using mouse standards (Crystal Chem, Downers Grove, IL, USA).

Diagnosis of diabetes Female offspring in control $(n=72)$ and undernourished groups $(n=67)$ were followed longitudinally with twice-weekly random glucose measurements for up to 28 weeks. Diabetes was defined as glucose $>13.9 \mathrm{mmol} / 1$ on two consecutive measurements. Once diabetes was diagnosed, mice were removed from the cohort.

Acceleration of diabetic phenotype in males The incidence of diabetes in NOD mice differs by sex. While both sexes develop insulitis, female mice develop diabetes at an earlier timepoint and more frequently than males [12]. We therefore administered cyclophosphamide $(200 \mathrm{mg} / \mathrm{kg}$, i.v., tail vein) to a subgroup of 12 -week-old males (control = 15 ; undernourished $=23$ ) to accelerate development of diabetes [13]. Glucose was measured every 2 days; diabetes was defined as glucose $>13.9 \mathrm{mmol} / \mathrm{l}$.

Pancreatic histology and insulitis scoring Offspring mice (12 males and 12 females, equally divided between control and undernourished groups) were killed at 12 weeks of age for assessment of insulitis severity. Mice were anaesthetised with pentobarbital $(40 \mathrm{mg} / \mathrm{kg}$ intraperitoneally) and pancreata were dissected, weighed, fixed in $4 \%$ paraformaldehyde, embedded in paraffin and sectioned at $7 \mu \mathrm{m}$ for haematoxylin and eosin staining. Sections were scored for insulitis (observers being blinded to group) as follows: grade $0=$ no insulitis; grade $1=$ peri-insulitis; grade $2=$ non-aggressive insulitis with lymphocytic infiltration in $<50 \%$ of the islet; grade $3=$ aggressive insulitis with lymphocytic infiltration in $>50 \%$ of the islet [14]. Three sections were scored per mouse, representing $43-135$ islets ( $85 \pm 5$ islets) per mouse.

Evaluation of beta cell mass Offspring in control and undernourished groups were killed at 14 days of life for measurement of total beta and non-beta cell mass via point counting morphometry [15]. Using a cocktail of antiglucagon and anti-somatostatin antibodies (Linco Research, St Charles, MO, USA) and anti-rabbit secondary anti- 
bodies, 3- to 5- $\mu \mathrm{m}$ sections were immunostained; these were developed with diaminobenzidine and counterstained with haematoxylin. A microscope was connected to a colour camera and monitor with a 48-point transparent overlay, and each block was scored systematically at a final magnification of $406 \times$. In non-overlapping fields, investigators counted intercepts over beta cells, endocrine nonbeta cells, exocrine pancreatic tissue and non-pancreatic tissue. Fifty fields were evaluated for each mouse [15]. Beta cell mass was calculated from the relative beta cell volume multiplied by the pancreatic weight.

Evaluation of apoptosis Mice in control and undernourished groups were killed at 14 days $(n=12), 12$ weeks $(n=$ 10 females) and 20 weeks ( $n=6$ females) for evaluation of pancreatic apoptosis. Pancreata were sectioned at $5 \mu \mathrm{m}$ for terminal deoxynucleotidyl transferase-mediated d-UTP nick-end labelling (TUNEL; Roche Diagnostics, Mannheim, Germany) [16].

Maternal and offspring leptin analysis Serum was collected from: (1) pregnant dams at 12.5 and 18.5 days of gestation; and (2) control and undernourished offspring at 4, 8, 12, 16, 20, 24 and 27 weeks for ELISA-based leptin measurement (Crystal Chem).

Dual-energy X-ray absorptiometry Dual-energy X-ray absorptiometry (DEXA; Lunar PIXImus Research Mouse Densitometer; GE Healthcare, Madison, WI, USA) was performed at 12, 16, 20 and 24 weeks to quantify fat mass, lean mass and bone density. Prior to testing, animals were sedated with tribromoethanol-tert-amyl alcohol (1:1, $0.015 \mathrm{ml} / \mathrm{g}$ body weight intraperitoneally).

Statistical analyses Results are expressed as mean \pm SEM. Cumulative diabetes incidence was modelled as a KaplanMeier survival function and significance calculated via logrank test. For group comparisons, analysis was performed using a two-tailed $t$ test assuming unequal variances unless otherwise specified (JMP Version 6.0.0; SAS Institute, Cary, NC, USA). For insulitis scoring, a $\chi^{2}$ test was performed (Web Chi-Square Calculator software, http://www. georgetown.edu/faculty/ballc/webtools/web_chi.html). We considered $p$ values less than 0.05 to be statistically significant.

\section{Results}

Birthweight and growth parameters We have previously established a mouse model of low birthweight related to maternal undernutrition during pregnancy [17]. Control NOD dams tended to give birth to larger litters (control: $8.59 \pm 0.45$ pups; undernourished: $7.32 \pm 0.52 ; p=0.07$ ). Litter size was normalised to five pups per nursing dam to minimise effects of litter size on postnatal growth. As expected, the birthweight of undernourished pups was reduced (control: $1.53 \pm 0.02 \mathrm{~g}$; undernourished: $1.24 \pm$ $0.02 \mathrm{~g} ; p=0.00003$ ) (Fig. 1a). The body weight of female undernourished offspring remained significantly lower than that of control offspring until 12 weeks of life, after which body weights were comparable.

Body composition Since growth curves suggested that undernourished mice had undergone postnatal catch-up growth, often accompanied by increased adiposity [18], we performed DEXA at 12, 16, 20 and 24 weeks. Fat mass (as percentage of body weight) at 24 weeks was significantly higher in the undernourished group than in controls (control: 20.3 $\pm 4.8 \%$; undernourished: $27.9 \pm 4.1 \%$; $p=$ 0.001 ) (Fig. 1b); similar trends were observed at 12, 16 and 20 weeks.

Diabetes incidence Prenatal undernutrition had a marked protective effect on development of diabetes. The cumulative diabetes incidence in females by age 24 weeks was $73 \%$ among controls and $48 \%$ in antenatally undernourished mice ( $p=0.003$ by log rank test) (Fig. 2a). Mean age at diagnosis of diabetes was $16.8 \pm 0.5$ weeks in control vs $17.8 \pm 0.9$ weeks in undernourished mice $(p=0.32)$; median age at diagnosis was 17 weeks in control vs 19 weeks in undernourished mice.
Fig. 1 a Birthweight in NOD mice exposed to intrauterine undernutrition compared with controls. b Per cent total body fat, as measured by DEXA scan, in NOD female offspring mice exposed to intrauterine undernutrition (open bars) vs controls (filled bars). $* * p<0.01$; $* * * p<0.001$
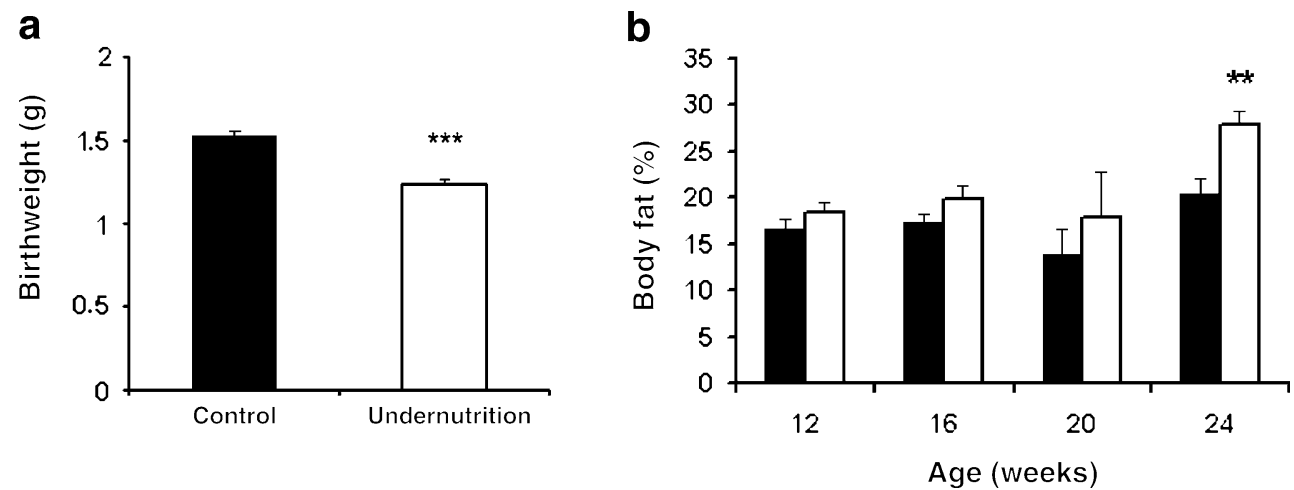
Fig. 2 Cumulative survival to diabetes diagnosis in (a) female NOD offspring $(n=101)$ and (b) male NOD offspring of control (thick lines) and undernutrition (thin lines) pregnancies $(n=101)$. Male NOD offspring $(n=38)$ were treated with cyclophosphamide on day 0 (at age 12 weeks). ${ }^{* *} p<0.01$ a

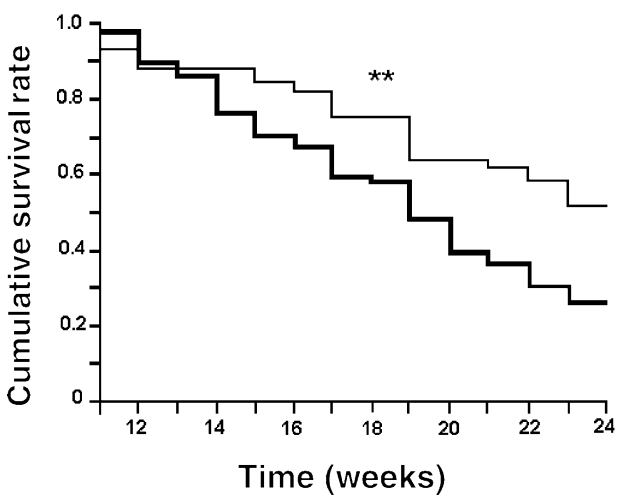

b

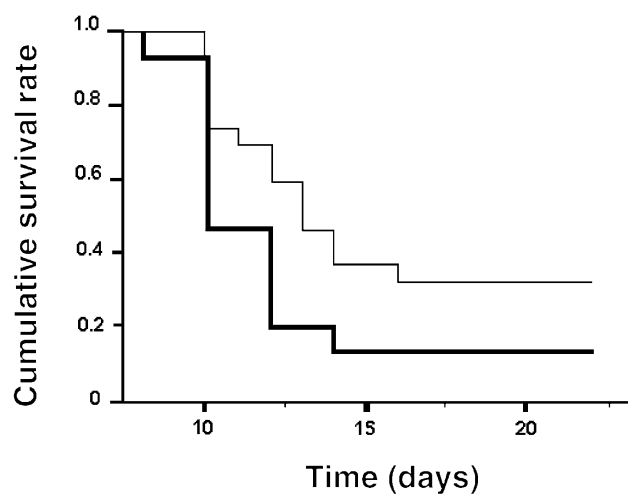

Although $90 \%$ of male NOD mice develop insulitis, only 20-30\% develop overt diabetes [19]. However, diabetes can be unmasked in males with cyclophosphamide [13]. Using this approach, we observed that the cumulative diabetes incidence 16 days after cyclophosphamide injection was $87 \%$ in controls and $68 \%$ in undernourished mice ( $p=0.058$, log rank test) (Fig. 2b). In addition, control males tended to develop diabetes earlier than undernourished males. The mean time of development of diabetes was $10.8 \pm 0.4$ days in controls vs $11.9 \pm 0.5$ days in the undernourished group $(p=0.1)$; median time was 10 days in controls and 12 in undernourished mice.

Glucose and insulin dynamics To assess between-group differences in glucose and insulin secretory patterns, we measured random-fed glucose and performed intraperitoneal glucose and insulin tolerance tests. Random-fed glucose levels remained similar between control and undernourished offspring until 14 weeks of age, after which glucose levels tended to increase in controls, coinciding with the development of diabetes (not shown). Glucose tolerance tests revealed minimal differences between groups, although the
AUC tended to be higher in control females both at 8 weeks

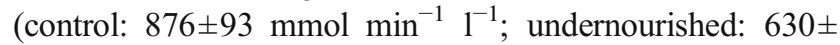
$35 \mathrm{mmol} \mathrm{min}{ }^{-1} 1^{-1} ; p=0.08$ ) (Fig. 3a) and 12 weeks (control: 1,039 $\pm 86 \mathrm{mmol} \mathrm{min}{ }^{-1} \mathrm{l}^{-1}$; undernourished: $850 \pm 79 \mathrm{mmol}$ $\min ^{-1} 1^{-1} ; p=0.11$, not shown).

Intraperitoneal insulin tolerance tests, performed in females at 8 and 12 weeks (Fig. 3b) and in males at 8 weeks, demonstrated no significant differences in insulin sensitivity between control and undernourished groups. Fasting insulin was similar at 8 weeks (control: $76 \pm$ $12 \mathrm{pmol} / 1$; undernourished: $59 \pm 8.6 \mathrm{pmol} / \mathrm{l} ; p=0.265$ ), but by 12 weeks fasting insulin was significantly higher in controls (control: $215 \pm 40 \mathrm{pmol} / \mathrm{l}$; undernourished: $83 \pm$ $16 \mathrm{pmol} / 1 ; p=0.008$ ) (Fig. 3c). There was no difference in fed insulin between undernourished and control females (not shown).

Pancreatic mass, histology and insulitis Pancreatic weight at 12 weeks, both in absolute values and as a percentage of body weight, did not differ between control and undernourished mice (control: $0.282 \pm 0.026 \mathrm{~g}$; undernourished: $0.276 \pm$ $0.011 \mathrm{~g} ; p=0.70$ ). Beta cell mass at age 14 days was also a

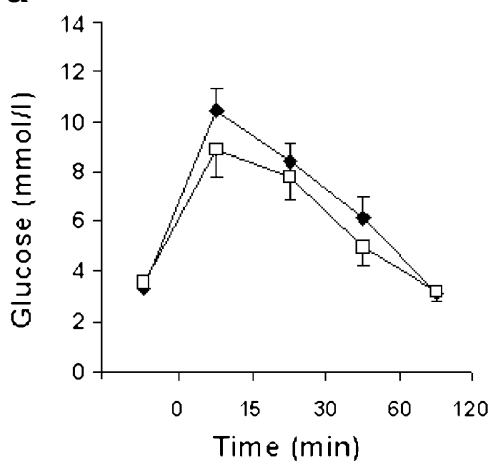

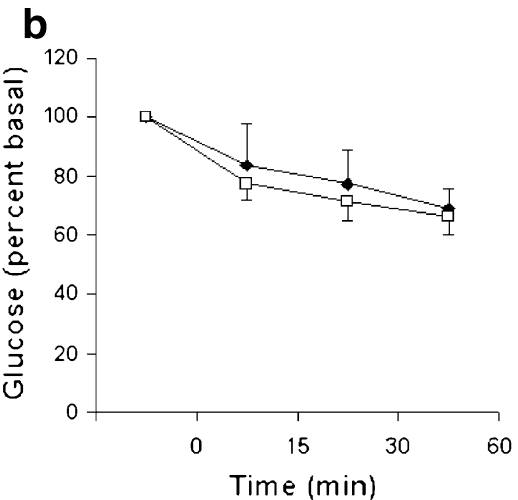

C

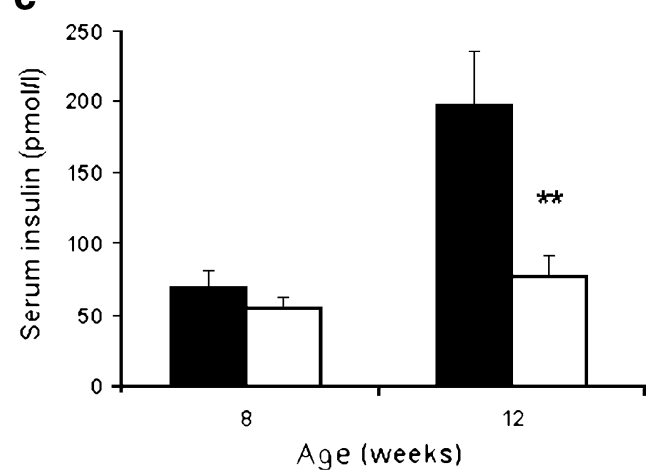

Fig. 3 Glucose tolerance test (a), insulin tolerance test (b) and fasting insulin levels (c) in female NOD offspring at 8 weeks and additionally (c) 12 weeks of age. Control group: filled symbols/bars; intrauterine undernutrition group: open symbols/bars. Glucose AUC (a) was not statistically different between the groups $(p=0.08)$. Glucose levels (b) are expressed as per cent of basal glucose level following insulin injection ( $1 \mathrm{U} / \mathrm{kg}$ intraperitoneally) at time $0 . \mathrm{z}^{* *} p<0.01$ for difference between control and undernourished groups at age 12 weeks 
a

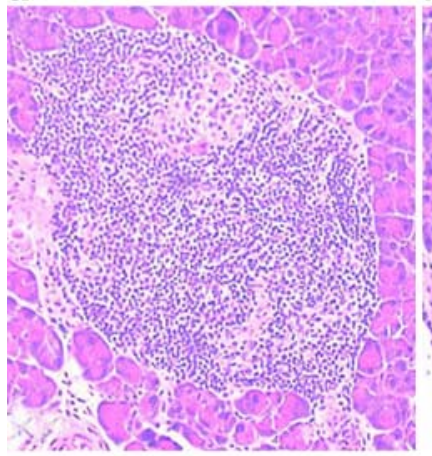

C

Control males

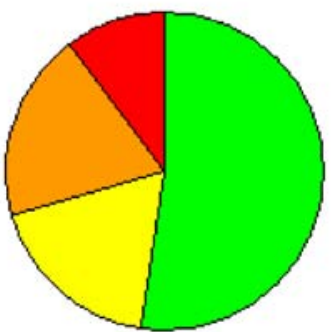

e

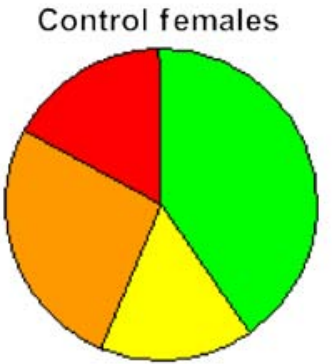

g

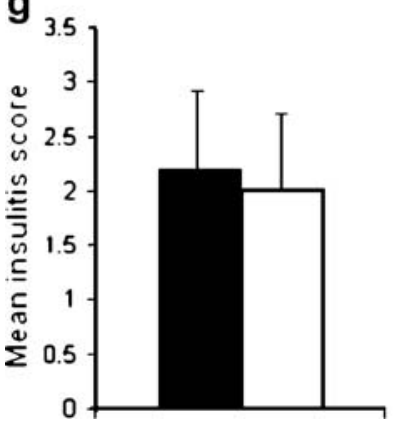

b

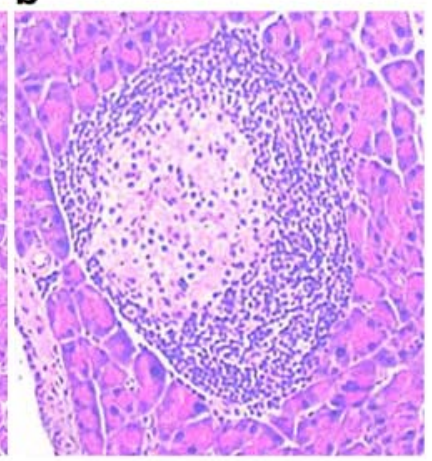

d UN males

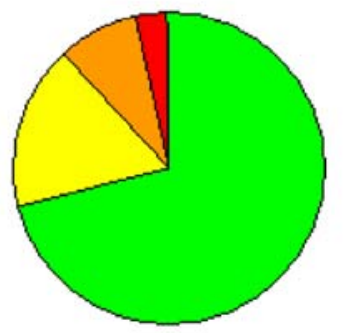

f UN females

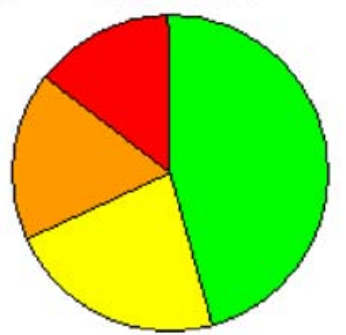

h

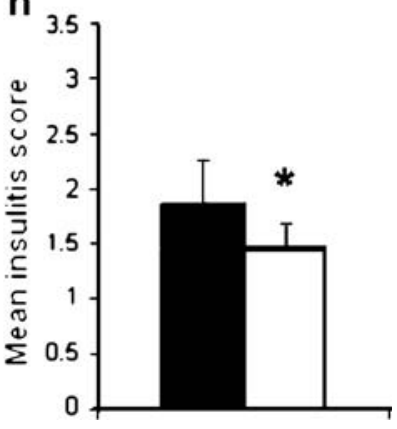

Fig. 4 Representative light micrographs of islets affected by insulitis in control $(C)$ (a) or intrauterine undernourished (UN) (b) offspring at age 12 weeks. Note differences in the extent of lymphocytic infiltration of the islet. Severity of insulitis at 12 weeks in control or intrauterine undernourished NOD offspring. c, control males; d, UN males; e, control females; f, UN females. Insulitis score: green, grade 0 ; yellow, grade 1; orange, grade 2; red, grade 3 . For male and female mice the distribution of insulitis severity was significantly different between control and undernourished groups $\left(p<0.001\right.$ by $\chi^{2}$ test). $\mathbf{g}$ Mean insulitis score in control (filled bars) and undernourished (open bars) females at 12 weeks. h Mean insulitis score in control and undernourished males at 12 weeks. Control group, filled bars; intrauterine undernourished group, open bars. ${ }^{*} p<0.05$
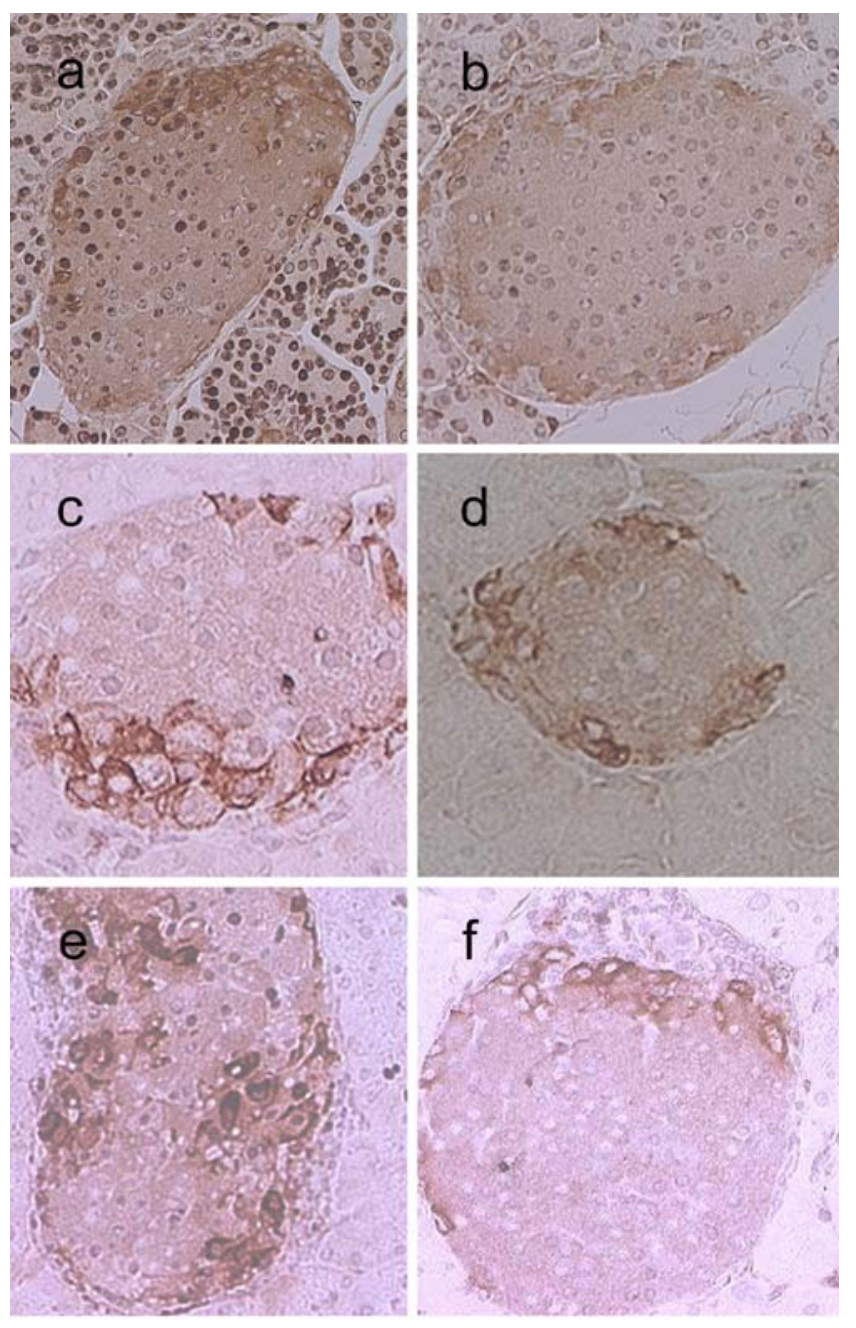

9

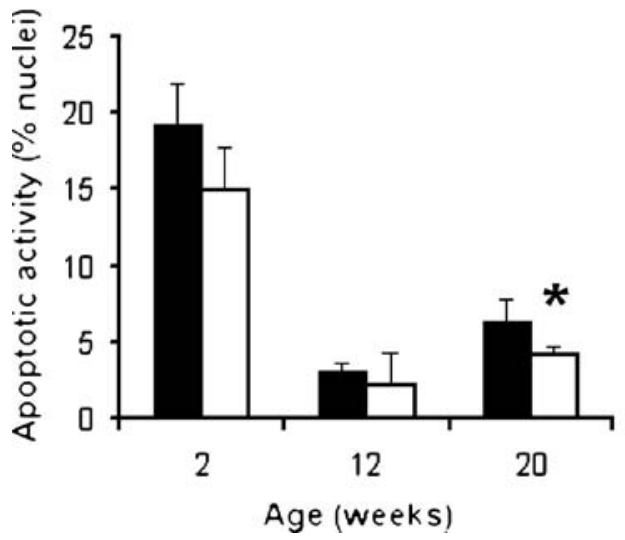

Fig. 5 Photomicrographs of TUNEL staining from pancreatic islets from control (a, c, e) and undernourished $(\mathbf{b}, \mathbf{d}, \mathbf{f})$ NOD offspring at 2 $(\mathbf{a}, \mathbf{b}), 12(\mathbf{c}, \mathbf{d})$ and $20(\mathbf{e}, \mathbf{f})$ weeks of age. $\mathbf{g}$ Quantitative assessment of apoptotic activity, as assessed by TUNEL positivity, in control (filled bars) and undernourished (open bars) mice. ${ }^{*} p<0.05$ 
similar between groups (control: $0.4 \pm 0.1 \mathrm{mg}$; undernourished: $0.5 \pm 0.10 \mathrm{mg} ; p=0.24)$.

Insulitis, i.e. monocytic/lymphocytic infiltration of pancreatic islet cells, is a pathological lesion that accompanies autoimmune diabetes in mice and humans [14]. To determine whether differences in diabetes incidence between control and undernourished NOD mice reflected differences in insulitis, we performed detailed histological evaluation of pancreatic islets. Light micrographs of representative islets are shown in Fig 4a,b. For both females and males, islets from controls were more likely to have severe (grade 2 or 3 ) than mild (grade 0 or 1 ) insulitis (Fig. 4c-f). In females, $40.4 \%$ of islets in controls were graded as severe, compared with $30.6 \%$ of islets in undernourished mice ( $p<0.01$ by $\chi^{2}$ test). Differences were even more striking in males, with $29.5 \%$ of control islets graded as severe, but only $12.3 \%$ graded as severe in undernourished mice $\left(p<0.001\right.$ by $\chi^{2}$ test). Mean insulitis scores for control and undernourished female mice were $2.2 \pm 0.73$ and $2.0 \pm 0.70$, respectively, at age 12 weeks ( $p=$ 0.63) (Fig. 4g). For males, mean insulitis scores were significantly lower in the undernourished group (control: $1.86 \pm 0.41$; undernourished: $1.43 \pm 0.26 ; p=0.05$ ) (Fig. $4 \mathrm{~h}$ ).

Apoptosis We hypothesised that rates of apoptosis would differ between control and undernourished offspring mice, given that apoptosis is the final common mechanism of pancreatic beta cell death in both spontaneous and cyclophosphamide-accelerated diabetes in NOD mice [20]. We therefore examined pancreatic sections from mice at 2 , 12 and 20 weeks of life to quantify the percentage of apoptotic beta cells. As seen in Fig. 5a, there was extensive evidence of apoptosis in islets at 2 weeks of age, consistent with the wave of apoptosis in normal islets during early postnatal life [21]. The overall pancreatic islet number and the percentage of apoptotic cells were lower by 20 weeks. However, control mice tended to have more extensive apoptosis than undernourished mice; these differences reached statistical significance at 20 weeks (control: $6.3 \pm$ 1.4\%; undernourished: $4.2 \pm 0.3 \%$; $p=0.05$ ) (Fig. $5 b$ ).
Serum leptin Leptin is an adipocyte-derived hormone that parallels nutritional status and contributes to satiety responses. Moreover, it may play an important role in immune responses and beta cell function [22]. Leptin levels did not differ between control and undernourished pregnant dams on day 12.5 of gestation (i.e. prior to diet restriction). However, by day 18.5 of gestation, leptin was significantly decreased in undernourished dams, probably reflecting decreased fat stores (control: 1,425 $\pm 406 \mathrm{pmol} / \mathrm{l}$; undernourished: $448 \pm 146 \mathrm{pmol} / \mathrm{l} ; p=0.03$ ) (Fig. 6a). Leptin levels were significantly higher in undernourished offspring at 4 weeks of age (control: $458 \pm 44 \mathrm{pmol} / 1$ vs undernourished: $589 \pm 41 \mathrm{pmol} / \mathrm{l} ; p=0.03)$. At 8 weeks they became similar, but increased again in undernourished mice after 20 weeks. By 27 weeks, leptin levels were nearly twofold higher in undernourished offspring (control: $598 \pm 86 \mathrm{pmol} /$ 1 vs undernourished: $1,114 \pm 162 \mathrm{pmol} / 1 ; p=0.004)$.

\section{Discussion}

Observational human studies support the hypothesis of an important role for the prenatal and early postnatal environment in shaping risk of type 1 diabetes. To determine whether prenatal nutrition modulates diabetes incidence in an experimental setting, we applied a model of maternal undernutrition and low birthweight to the diabetes-prone NOD mouse. We demonstrate that a $40 \%$ reduction in maternal nutrition during the final week of gestation reduces the incidence of diabetes in female NOD offspring by $35 \%$. Similarly, male offspring of undernourished mothers demonstrated a modest degree of protection from the diabetogenic effects of cyclophosphamide, although these differences did not reach statistical significance. Undernourished mice were $19 \%$ less likely than controls to have overt diabetes 16 days after cyclophosphamide injection; the undernourished mice that did develop diabetes did so almost 2 days later than controls.

Our model of low birthweight appears to exert its protective effects via changes in insulitis, an inflammatory
Fig. 6 Leptin levels of control (filled bars/symbols) and undernourished (open bars/symbols) pregnant female NOD mice (a) and female NOD offspring by age (b). $* p<0.05 ; * * p<0.01$
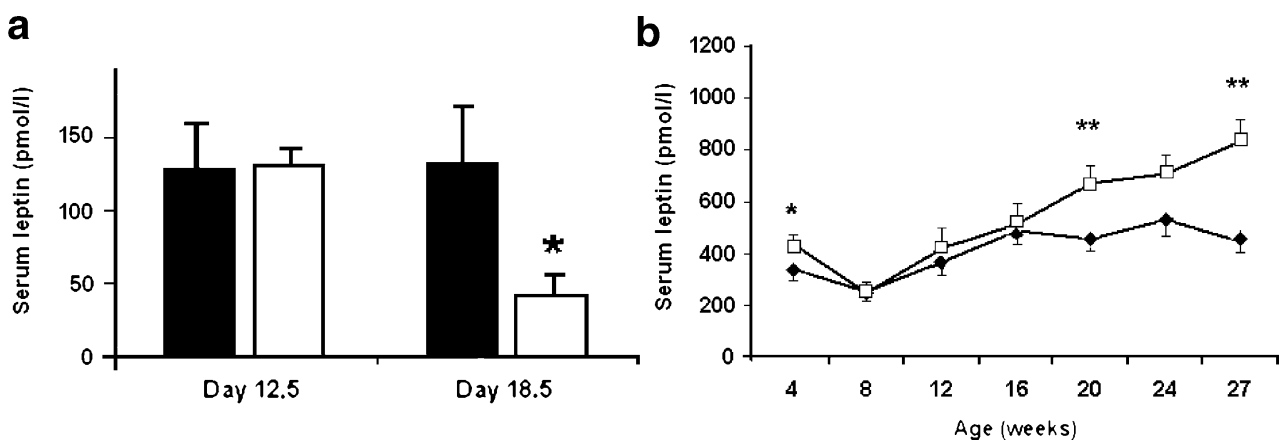
lesion that accompanies the development of diabetes in NOD mice and humans. There is some controversy as to whether insulitis in itself is pathological, as many NOD mice with histological evidence of insulitis (particularly males) never progress to overt diabetes [12]. Rather, the progression from insulitis to overt diabetes appears to be a complex, coordinated process involving $\mathrm{T}$ helper cells, macrophages and natural killer cells, loss of $\mathrm{T}$ suppressor cells and, ultimately, release of cytokines with direct toxicity to beta cells (IFN- $\gamma$, IL-1 $\beta$, IL-6) [23]. In our experiment, undernourished mice had significantly less severe insulitis than control mice. Thus, the lower incidence of diabetes observed in undernourished female offspring is likely to reflect reduced progression from innocuous insulitis to destructive insulitis. Moreover, diabetes was delayed and reduced in incidence in undernourished males following cyclophosphamide treatment, a finding suggesting protection from cyclophosphamide-induced insulitis and/or macrophage and lymphocyte activation [24]. It will be important for future research to examine specific mechanisms by which in utero undernutrition affects the immunological chain of events leading from insulitis to diabetes in NOD mice.

Beta cell apoptosis is a late event in the cascade leading to autoimmune diabetes in mouse and man [20]. Apoptosis was reduced in undernourished as compared with control mice at age 20 weeks, a time course that parallels the decreased incidence of diabetes in undernourished offspring. While apoptosis is a key effector of immune destruction, interestingly, it is also central to the process of pancreatic remodelling that occurs in the early postnatal period in rodents [21]. A similar process is thought to occur during late gestation and early postnatal life in humans. It has been speculated that this remodelling period may affect risk of diabetes through selection of beta cell populations that may be more or less vulnerable to autoimmunity. We did not, however, detect any differences in apoptosis or in beta cell mass between control and undernourished mice at 14 days. Nonetheless, it is interesting to speculate that the beta cell populations emerging during this time may differ in their functional capacity.

While the adipocyte-derived hormone leptin was initially identified as a major regulator of body weight, energy balance and endocrine function, leptin also has effects in the beta cell, decreasing insulin expression and secretion [25], as well as inhibiting apoptosis [26]. Conversely, leptin also enhances pro-inflammatory autoimmune responses [22] and accelerates diabetes in female NOD mice, perhaps by increasing IFN- $\gamma$ secretion [27]. Leptin-resistant NOD/ LtJ mice harbouring the Lepr $^{\mathrm{db}-5 \mathrm{~J}}$ leptin receptor point mutation (which reduces receptor dimerisation but permits limited leptin signalling) are protected from insulitis and autoimmune diabetes despite early-onset obesity and hyper- insulinaemia, perhaps via inhibition of $\mathrm{T}$ cell effector responses [28]. In our experimental protocol, leptin was significantly elevated in undernourished offspring, consistent with postnatal 'catch-up' growth, increased adiposity and, perhaps, leptin resistance. It is interesting that while insulin levels in Lepr ${ }^{\mathrm{db}-5 \mathrm{~J}}$ mice are increased (in contrast to our undernourished mice), leptin levels in the undernourished and in Lepr ${ }^{\mathrm{db}-5 \mathrm{~J}}$ diabetes-resistant mice are increased. The question of how these differences in leptin and leptin signalling are mechanistically linked to the reduction in autoimmune diabetes in undernourished mice will be an important subject of future study. It will also be important to elucidate how other adipocyte-derived hormones, such as adiponectin (which is reduced in low-birthweight human infants [29] and, like leptin, has immunomodulatory properties [30]), affect autoimmune diabetes risk.

The 'beta cell rest' hypothesis proposes that endogenous beta cell activity affects the natural history of type 1 diabetes, and that strategies to decrease insulin secretion (e.g. diazoxide, exogenous insulin) may preserve beta cell function and delay diabetes onset [31]. Conversely, increased insulin demand may aggravate beta cell autoimmunity due to increased antigen expression. Although strategies to decrease insulin secretion have not been effective in humans [32], we wished to determine whether differences in insulin secretion that were present prior to the onset of insulitis could account for some of the differences in diabetes incidence between undernourished and control mice. Although fed insulin levels did not differ, fasting insulin was significantly lower in undernourished mice. These data are consistent with the reductions in either intrinsic insulin secretory capacity or beta cell mass that have been observed in models of antenatal undernutrition $[17,33,34]$ and which may, in turn, reduce antigenic stimulus and beta cell autoimmunity in our model.

While our findings are potentially consistent with the beta cell rest paradigm, metabolic factors may also contribute to observed differences in diabetes risk. Although insulin tolerance testing demonstrated equivalent wholebody insulin sensitivity, we cannot exclude the possibility that tissue-specific insulin sensitivity differed as a function of prenatal nutrition and contributed to altered beta cell physiology. For example, experimental disruption of insulin action within the beta cell reduces insulin secretion in rodents [35]. Similarly, alterations in insulin sensitivity or differentiation state in adipose tissue may modulate beta cell function, via altered secretion of adipocytokines (e.g. visfatin) [36]. Thus, both immunological and metabolic factors may contribute to the reduction in diabetes risk associated with antenatal undernutrition.

Although the effects of in utero undernutrition on diabetes incidence in NOD mice have not, to our knowledge, been previously studied, our findings are 
consistent with human data linking birthweight and type 1 diabetes risk. In a large prospective cohort of Norwegian children, the risk of diabetes increased linearly with increasing quintiles of birthweight, with infants in the top quintile $(>4,500 \mathrm{~g})$ having double the risk of diabetes as compared with infants in the lowest quintile $(<2,000 \mathrm{~g})$ [2]. Similarly, a large European case-control study demonstrated a threefold reduction in diabetes risk among low-birthweight infants [3]. Other epidemiological studies, however, have failed to demonstrate a clear association between birthweight and type 1 diabetes risk $[37,38]$ or have only found a link between birthweight and diabetes before age 10 years [39].

In humans, the interpretation of studies implicating low birthweight is complex, as birthweight is influenced by parity, pregnancy complications, maternal age, nutrition, placental function and genetic determinants both of size at birth and of later diabetes incidence (e.g. HLA DQ [40]). Our experimental model allowed us to verify the importance of the intrauterine nutritional environment in isolation from other determinants of birthweight in modifying diabetes risk, which represents an advantage over human observational studies in this area. However, caution should be exercised when extrapolating our findings to humans, as placental insufficiency, and not maternal undernutrition, is the most common cause of low birthweight in Western countries. A second challenge when interpreting our findings stems from the difficulty in separating the effects of in utero undernutrition from subsequent consequences of undernutrition, namely, the 'catch-up' growth that follows periods of suboptimal nutrition. It is critical to understand these distinctions, as human data suggest that periods of rapid weight and height gain tend to precede type 1 diabetes $[10,11]$; it is not clear whether the nutritional environment or accompanying patterns of growth, hormonal secretion or metabolism contribute to diabetes risk.

Data from animal models, however, do in fact indicate that nutritional status is a key determinant of diabetes risk. Alternating periods of feeding and fasting reduces diabetes incidence in BioBreeding rats [41], while a high-protein diet hastens diabetes [42] and protein-rich high-fat diets accelerate beta cell loss by apoptosis in pre-diabetic NOD mice [43]. Moreover, infusions of fatty acids or glucose induce apoptosis in rat islets, an effect reversed by leptin [44]. Thus, the protective effects of antenatal undernutrition on the incidence of diabetes may be mediated through prevention of apoptosis [45]; further studies will be required to test this hypothesis.

Immune modulation is another mechanism that may underlie the association between birthweight and risk of type 1 diabetes. In humans, low-birthweight neonates have defects in humoral and cell-mediated immunity [46]. These immune deficits have been documented from the perinatal period into adolescence [47], leading to the hypothesis that the immune system, like the endocrine and cardiovascular systems, may be 'programmed' in utero.

Further evidence for the immunomodulatory properties of undernutrition comes from animal studies. In mice, undernutrition forestalls development of autoimmune renal disease and blunts other manifestations of autoimmunity. Moreover, in rats, lifelong food restriction reduces antigentriggered memory $\mathrm{T}$ cell responses and increases levels of the anti-inflammatory interleukin IL-2, while lowering levels of IL- 6 and TNF- $\alpha$. Restriction of energy intake increases circulating corticosterone levels, which in turn enhances negative selection of potentially autoreactive CD4-CD8 cells in thymus [48]. Maternal undernutrition during gestation may also decrease transplacental transmission of islet antibodies, a process which can also contribute to diabetes in NOD mice [49]. While our experiment showed a significant effect of intrauterine undernutrition on the degree of insulitis in NOD mice, suggesting that immune responses are altered in our low-birthweight model, we did not measure anti-islet antibodies, corticosterone, lymphocyte numbers or activity, or cytokines. Future studies measuring these markers should help to delineate the immunological mechanisms through which intrauterine undernutrition reduces risk of type 1 diabetes.

In conclusion, in utero undernutrition protects NOD mice from spontaneous and cyclophosphamide-induced autoimmune diabetes. These findings are consistent with observed epidemiological links between birthweight and risk of type 1 diabetes in humans. Furthermore, our experimental data suggest that leptin and/or leptin resistance may play a potential role in altering levels of insulitis and beta cell apoptosis, thus modifying the onset of diabetes. Identifying precise metabolic and immunological mechanisms for the protective effects of antenatal undernutrition and low birthweight will be an important area for future investigation.

Acknowledgements The authors gratefully acknowledge grant support from National Institutes of Health (DK 062948) and the Adler Foundation.

Duality of interest The authors declare that no duality of interest exists in connection with this work.

\section{References}

1. Gluckman PD, Hanson MA (2004) Living with the past: evolution, development, and patterns of disease. Science 305:1733-1736

2. Stene LC, Magnus P, Lie RT, Sovik O, Joner G; Norwegian Childhood Diabetes Study Group (2001) Birth weight and childhood onset type 1 diabetes: population based cohort study. BMJ 322:889-892 
3. Dahlquist GG, Patterson C, Soltesz G (1999) Perinatal risk factors for childhood type 1 diabetes in Europe. The EURODIAB Substudy 2 Study Group. Diabetes Care 22:1698-1702

4. Podar T, Onkamo P, Forsen T, Karvonen M, Tuomilehto-Wolf E, Tuomilehto J (1999) Neonatal anthropometric measurements and risk of childhood-onset type 1 diabetes. DiMe Study Group. Diabetes Care 22:2092-2094

5. Rich-Edwards JW, Colditz GA, Stampfer MJ et al (1999) Birthweight and the risk for type 2 diabetes mellitus in adult women. Ann Intern Med 130:278-284

6. Dahlquist G, Bennich SS, Kallen B (1996) Intrauterine growth pattern and risk of childhood onset insulin dependent (type I) diabetes: population based case-control study. BMJ 313:11741177

7. Cardwell CR, Carson DJ, Patterson CC (2005) Parental age at delivery, birth order, birth weight and gestational age are associated with the risk of childhood Type 1 diabetes: a UK regional retrospective cohort study. Diabet Med 22:200-206

8. Dorner G, Thoelke H, Mohnike A, Schneider H (1985) High food supply in perinatal life appears to favour the development of insulin-treated diabetes mellitus (ITDM) in later life. Exp Clin Endocrinol 85:1-6

9. Kimpimaki T, Kulmala P, Savola K et al (2002) Natural history of beta-cell autoimmunity in young children with increased genetic susceptibility to type 1 diabetes recruited from the general population. J Clin Endocrinol Metab 87:4572-4579

10. Johansson C, Samuelsson U, Ludvigsson J (1994) A high weight gain early in life is associated with an increased risk of type 1 (insulin-dependent) diabetes mellitus. Diabetologia 37:91-94

11. Blom L, Persson LA, Dahlquist G (1992) A high linear growth is associated with an increased risk of childhood diabetes mellitus. Diabetologia 35:528-533

12. Bao M, Yang Y, Jun HS, Yoon JW (2002) Molecular mechanisms for gender differences in susceptibility to $\mathrm{T}$ cell-mediated autoimmune diabetes in nonobese diabetic mice. J Immunol 168:5369-5375

13. Harada M, Makino S (1984) Promotion of spontaneous diabetes in non-obese diabetes-prone mice by cyclophosphamide. Diabetologia 27:604-606

14. Matsumoto M, Yagi H, Kunimoto K, Kawaguchi J, Makino S, Harada M (1993) Transfer of autoimmune diabetes from diabetic NOD mice to NOD athymic nude mice: the roles of T cell subsets in the pathogenesis. Cell Immunol 148:189-197

15. Montana E, Bonner-Weir S, Weir GC (1993) Beta cell mass and growth after syngeneic islet cell transplantation in normal and streptozotocin diabetic $\mathrm{C} 57 \mathrm{BL} / 6$ mice. J Clin Invest 91:780-787

16. Gavrieli Y, Sherman Y, Ben-Sasson SA (1992) Identification of programmed cell death in situ via specific labeling of nuclear DNA fragmentation. J Cell Biol 119:493-501

17. Jimenez-Chillaron JC, Hernandez-Valencia M, Reamer $C$ et al (2005) Beta-cell secretory dysfunction in the pathogenesis of low birth weight-associated diabetes: a murine model. Diabetes 54:702-711

18. Jimenez-Chillaron JC, Hernandez-Valencia M, Lightner A et al (2006) Reductions in caloric intake and early postnatal growth prevent glucose intolerance and obesity associated with low birthweight. Diabetologia 49:1974-1984

19. Lampeter EF, Signore A, Gale EA, Pozzilli P (1989) Lessons from the NOD mouse for the pathogenesis and immunotherapy of human type 1 (insulin-dependent) diabetes mellitus. Diabetologia 32:703-708

20. Augstein P, Elefanty AG, Allison J, Harrison LC (1998) Apoptosis and beta-cell destruction in pancreatic islets of NOD mice with spontaneous and cyclophosphamide-accelerated diabetes. Diabetologia 41:1381-1388
21. Scaglia L, Cahill CJ, Finegood DT, Bonner-Weir S (1997) Apoptosis participates in the remodeling of the endocrine pancreas in the neonatal rat. Endocrinology 138:1736-1741

22. Fantuzzi G (2005) Adipose tissue, adipokines, and inflammation. J Allergy Clin Immunol 115:911-919

23. Andre-Schmutz I, Hindelang C, Benoist C, Mathis D (1999) Cellular and molecular changes accompanying the progression from insulitis to diabetes. Eur J Immunol 29:245-255

24. Matos M, Park R, Mathis D, Benoist C (2004) Progression to islet destruction in a cyclophosphamide-induced transgenic model: a microarray overview. Diabetes 53:2310-2321

25. Seufert J (2004) Leptin effects on pancreatic beta-cell gene expression and function. Diabetes 53(Suppl 1):S152-S158

26. Okuya S, Tanabe K, Tanizawa Y, Oka Y (2001) Leptin increases the viability of isolated rat pancreatic islets by suppressing apoptosis. Endocrinology 142:4827-4830

27. Matarese G, Sanna V, Lechler RI et al (2002) Leptin accelerates autoimmune diabetes in female NOD mice. Diabetes 51:13561361

28. Lee CH, Reifsnyder PC, Naggert JK et al (2005) Novel leptin receptor mutation in NOD/LtJ mice suppresses type 1 diabetes progression: I. Pathophysiological analysis. Diabetes 54:2525-2532

29. Kamoda T, Saitoh H, Saito M, Sugiura M, Matsui A (2004) Serum adiponectin concentrations in newborn infants in early postnatal life. Pediatr Res 56:690-693

30. Sennello JA, Fayad R, Morris AM et al (2005) Regulation of T cell-mediated hepatic inflammation by adiponectin and leptin. Endocrinology 146:2157-2164

31. Aaen K, Rygaard J, Josefsen K et al (1990) Dependence of antigen expression on functional state of beta-cells. Diabetes 39:697-701

32. Diabetes Prevention Trial-Type 1 Diabetes Study Group (2002) Effects of insulin in relatives of patients with type 1 diabetes mellitus. N Engl J Med 346:1685-1691

33. Petry CJ, Ozanne SE, Wang CL, Hales CN (2000) Effects of early protein restriction and adult obesity on rat pancreatic hormone content and glucose tolerance. Horm Metab Res $32: 233-239$

34. Simmons RA, Templeton LJ, Gertz SJ (2001) Intrauterine growth retardation leads to the development of type 2 diabetes in the rat. Diabetes 50:2279-2286

35. Kulkarni RN, Bruning JC, Winnay JN, Postic C, Magnuson MA, Kahn CR (1999) Tissue-specific knockout of the insulin receptor in pancreatic b cells creates an insulin secretory defect similar to that in Type 2 diabetes. Cell 96:329-339

36. Fukuhara A, Matsuda M, Nishizawa M et al (2005) Visfatin: a protein secreted by visceral fat that mimics the effects of insulin. Science 307:426-430

37. Lawler-Heavner J, Cruickshanks KJ, Hay WW, Gay EC, Hamman RF (1994) Birth size and risk of insulin-dependent diabetes mellitus (IDDM). Diabetes Res Clin Pract 24:153-159

38. Bock T, Pedersen CR, Volund A, Pallesen CS, Buschard K (1994) Perinatal determinants among children who later develop IDDM. Diabetes Care 17:1154-1157

39. Dahlquist GG, Pundziute-Lycka A, Nystrom L (2005) Birthweight and risk of type 1 diabetes in children and young adults: a population-based register study. Diabetologia 48:1114-1117

40. Larsson HE, Lynch K, Lernmark B et al (2005) Diabetesassociated HLA genotypes affect birthweight in the general population. Diabetologia 48:1484-1491

41. Pedersen CR, Hagemann I, Bock T, Buschard K (1999) Intermittent feeding and fasting reduces diabetes incidence in BB rats. Autoimmunity 30:243-250

42. Schneider K, Laube H, Linn T (1996) A diet enriched in protein accelerates diabetes manifestation in NOD mice. Acta Diabetol $33: 236-240$ 
43. Linn T, Strate C, Schneider K (1999) Diet promotes beta-cell loss by apoptosis in prediabetic nonobese diabetic mice. Endocrinology 140:3767-3773

44. Shimabukuro M, Wang MY, Zhou YT, Newgard CB, Unger RH (1998) Protection against lipoapoptosis of beta cells through leptin-dependent maintenance of Bcl-2 expression. Proc Natl Acad Sci U S A 95:9558-9561

45. Piro S, Anello M, Di Pietro C et al (2002) Chronic exposure to free fatty acids or high glucose induces apoptosis in rat pancreatic islets: possible role of oxidative stress. Metabolism 51:1340-1347

46. Thilaganathan B, Plachouras N, Makrydimas G, Nicolaides KH (1993) Fetal immunodeficiency: a consequence of placental insufficiency. Br J Obstet Gynaecol 100:10001004

47. McDade TW, Beck MA, Kuzawa C, Adair LS (2001) Prenatal undernutrition, postnatal environments, and antibody response to vaccination in adolescence. Am J Clin Nutr 74: $543-548$

48. Wilder RL (1995) Neuroendocrine-immune system interactions and autoimmunity. Annu Rev Immunol 13:307-338

49. Kagohashi Y, Udagawa J, Abiru N, Kobayashi M, Moriyama K, Otani H (2005) Maternal factors in a model of type 1 diabetes differentially affect the development of insulitis and overt diabetes in offspring. Diabetes 54:2026-2031 